\title{
Spatial access disparities to primary health care in rural and remote Australia
}

\author{
Matthew Richard McGrail,1,2 John Stirling Humphreys ${ }^{1,2}$ \\ 'School of Rural Health, Monash University, Churchill; ${ }^{2}$ Centre of Research Excellence in \\ Rural and Remote Primary Health Care, Bendigo, Victoria, Australia
}

\begin{abstract}
Poor spatial access to health care remains a key issue for rural populations worldwide. Whilst geographic information systems (GIS) have enabled the development of more sophisticated access measures, they are yet to be adopted into health policy and workforce planning. This paper provides and tests a new national-level approach to measuring primary health care (PHC) access for rural Australia, suitable for use in macro-level health policy. The new index was constructed using a modified two-step floating catchment area method framework and the smallest available geographic unit. Primary health care spatial access was operationalised using three broad components: availability of PHC (general practitioner) services; proximity of populations to PHC services; and PHC needs of the population. Data used in its measurement were specifically chosen for accuracy, reliability and ongoing availability for small areas. The resultant index reveals spatial disparities of
\end{abstract}

Correspondence: Matthew R. McGrail, School of Rural Health, Monash University, Northways Road, Churchill, Victoria 3842, Australia. Tel: +61.3.5122.7394 - Fax: +61.3.5122.7841.

E-mail: matthew.mcgrail@monash.edu

Key words: Spatial accessibility; 2SFCA method; Rural health; Health services; Geographical disparities.

Acknowledgements: all authors are members of the Centre of Excellence for research in accessible and equitable primary health service provision in rural and remote Australia. The research reported in this paper is a project of the Australian Primary Health Care Research Institute (APHCRI), which is supported by a grant from the Australian Government Department of Health and Ageing. The information and opinions contained in it do not necessarily reflect the views or policy of the APHCRI or the Australian Government Department of Health and Ageing. Additionally, we acknowledge the contribution of Dr. Bernadette Ward, Monash University School of Rural Health, for leading our related 2012 study of the differences in travel behaviour for PHC access of rural residents by geography type.

Received for publication: 20 March 2015.

Revision received: 9 July 2015.

Accepted for publication: 12 August 2015.

CCopyright M.R. McGrail and J.S. Humphreys, 2015

Licensee PAGEPress, Italy

Geospatial Health 2015; 10:358

doi:10.4081/gh.2015.358

This article is distributed under the terms of the Creative Commons Attribution Noncommercial License (by-nc 3.0) which permits any noncommercial use, distribution, and reproduction in any medium, provided the original author(s) and source are credited. access to PHC across rural Australia. While generally more remote areas experienced poorer access than more populated rural areas, there were numerous exceptions to this generalisation, with some rural areas close to metropolitan areas having very poor access and some increasingly remote areas having relatively good access. This new index provides a geographically-sensitive measure of access, which is readily updateable and enables a fine granulation of access disparities. Such an index can underpin national rural health programmes and policies designed to improve rural workforce recruitment and retention, and, importantly, health service planning and resource allocation decisions designed to improve equity of $\mathrm{PHC}$ access.

\section{Introduction}

Rural populations of geographically large, developed countries such as Australia, the USA and Canada continue to experience poorer health outcomes than metropolitan populations (AIHW, 2008; Jones et al., 2009; Kulig and Williams, 2011). A consistent contributor to these health differentials is the poorer spatial access to health care for rural residents, both to primary health care (PHC) services as well as more centralised specialist care (Sibley and Weiner, 2011; Wakerman and Humphreys, 2012). Geography is widely acknowledged as a critical component of health care access, most notably for dispersed rural and remote populations. Overcoming poor access and significant geographical barriers to PHC services is the key to ensuring that rural and remote residents can use services in a timely manner and thereby improve health outcomes.

Access remains a global concern for health policy makers and health planners, most notably in relation to the equitable provision of PHC services for rural populations (Higgs, 1999). PHC provides the entry point for most people to the health system and is the most efficient and effective means to reduce health inequities (Starfield, 2006; WHO, 1978). Moreover, the delivery of PHC is sustainable within small rural and remote populations where most specialist health care is not (Thomas et al., 2014). Regrettably, rural access problems are most prominent in geographically large countries characterised by sparsely distributed populations and challenging geographical environments, both developed and developing ones (Humphreys and Solarsh, 2008), where residents experience significant spatial barriers to accessing services. Therefore, identification of access disparities to rural PHC services remains the key focus of rural health service planners and policy makers.

The concept of access to health care is complex and thus difficult to define and measure. The seminal paper by Penchansky and Thomas (1981) defined five components of access: availability; accessibility; affordability; acceptability; and accommodation, with additional components including timeliness and awareness (Russell et al., 2013). 
These components can be differentiated between spatial and aspatial, whilst specific barriers to access have both service-level and consumerlevel aspects. Ideally, access scores represent the fit between health service and population aspects over one or more components (Levesque et al., 2013; Russell et al., 2013).

Rural health policies continue to utilise simple access measures, notably using either generic classifications of rurality or remoteness or regional-level provider-to-population (PPR) measures (McGrail and Humphreys, 2009b; Ricketts et al., 2007). Furthermore, three approaches dominate the wider measurement of spatial accessibility. Firstly, travel impedance to the nearest service is a simple measure but ignores bypassing (where more distant services are utilised - common in PHC utilisation) as well as demand on limited services. Secondly, gravity models account for diminishing attractiveness with increased distance, and demand from the population for limited services (Guagliardo, 2004; Luo and Wang, 2003), but its decay function is questionable and difficult to define. Thirdly, PPRs account for demand and provide an easily understood and comparable access score (WHO, 2013); however PPRs are limited to pre-defined regions, where it is incorrectly assumed that no utilisation occurs across different regions and further assumed that distance remains a negligible barrier within regions (McGrail, 2012).

Over the past decade, the two-step floating catchment area (2SFCA) method has grown in prominence as the preferred measure of spatial access to PHC (Luo and Qi, 2009; Luo and Wang, 2003; McGrail and Humphreys, 2009c; Wan et al., 2012). Using more sophisticated geographic information systems (GIS) methodologies, its key design feature consists of overlapping catchments of both service provision and resident utilisation, with such catchments able to better match the unrestricted nature of open market primary level health care systems. Its design is particularly suited to applications in rural areas, though the choice of catchment size(s) becomes more problematic as the variation of population density increases (McGrail and Humphreys, 2014). Availability, relative to demand, and distance between services and residents are the main components of the 2SFCA method.

The 2SFCA method brings together elements of both PPRs and gravity models. The significant advancements of the 2SFCA method are twofold: its use of catchments centred on actual population and service locations; and its ability to integrate distance-decay functions defined to match healthcare utilisation behaviour (McGrail, 2012). Notably, the 2SFCA method is only limited by the resolution of the data inputs, which enable small area discrimination of results, and eliminates any concerns about using pre-defined regions (Bullen et al., 1996).

The 2SFCA methodology has received numerous strong commendations for its potential usage in health service planning from developed countries (Luo and Whippo, 2012; McGrail and Humphreys, 2009a; Wan et al., 2012; Wang and Luo, 2005) and has recently been tested in developing countries (Hu et al., 2013; Ranga and Panda, 2014). However, the value and validity of the 2SFCA as a method appropriate for the state/province level or national level, access measurement and resulting applications in rural health planning and policy remains unanswered. This paper utilises a modified 2SFCA method to provide and test a new national-level approach to measuring PHC access for rural Australia, hereafter referred to as the Index of Access.

\section{Materials and Methods}

An overview of the 2SFCA method used for this study, including equations used in its calculation, is provided in Figure 1. Within Step
1, the 2SFCA method calculates potential demand for a service by identifying all population locations within a fixed radius (up to a maximum time or distance, $\mathrm{d}_{\max }$ ) and aggregating demand from those residents. Similarly, Step 2 identifies all service locations that fall within a fixed radius (up to a maximum time or distance, $d_{\max }$ ) from each population location, and aggregates Step 1 scores to calculate an overall access score for each population location, in the same form as PPRs. Key advantages of this method include: i) enabling a superior measure of rural access to PHC that incorporates three critical health service utilisation components (availability, proximity, health needs); ii) providing a dynamic and timely measure of access to PHC that can be regularly updated using readily available data; and iii) providing a more sensitive measure of access to $\mathrm{PHC}$ based on utilising small-scale rural geographical data.

The study area was all of rural and remote Australia. Despite its landmass of 7.7 million $\mathrm{km}^{2}$, Australia is a highly urbanised country with around $70 \%$ of its 23 million residents located in large and mostly coastal metropolitan cities, which cover only $0.2 \%$ of its land. The remaining $30 \%$ ( 7 million) residents are highly dispersed, with $28 \%$ of residents considered rural and a little over $2 \%$ considered remote, residing within 13.4 and $86.4 \%$ of Australia's land mass, respectively.

For such a large country with vast differences in population density, the use of a single catchment size for all populations in the 2SFCA method is problematic (Luo and Whippo, 2012; McGrail, 2012; McGrail and Humphreys, 2014). It is recognised that residents in more sparsely-populated areas are prepared to travel further to access healthcare than in densely-populated regions (Buzza et al., 2011; McGrail et al., 2015; Tanser et al., 2006). A key feature for this study is the use of five catchment size levels defined in line with the Australian Bureau of Statistics' (ABS's) five remoteness levels under the Australian Statistical Geography Standard, i.e. the Remoteness Area (ASGS-RA) classification (ABS, 2011), such that both catchment size and preof volume $\mathrm{S}$ determine what population size (summed $\mathrm{P}_{\mathrm{k}}$ ) can potentially access that provider (up to the catchment border $=\mathrm{d}_{\max }$ ) and calculate the ratio of providers to the population $\left(R_{i}\right)$

$$
\operatorname{Rj}=\operatorname{Sj} / \Sigma \mathrm{k} \in\left[\mathrm{d}_{j k}<\mathrm{d}_{\max }\right] \mathrm{P}_{\mathrm{k}} * \mathrm{HN}_{\mathrm{k}} * \mathrm{f}\left(\mathrm{d}_{j \mathrm{k}}\right)
$$

STEP 2 Calculate population catchments - for each population location (i), determine what services (j) can potentially be accessed by that population (up to the catchment border $=\mathrm{d}_{\mathrm{mur}}$ ), and aggregate the PPRs for these services $\left(R_{j}\right)$ as calculated in STEP 1. The resultant score $\left(\mathrm{A}_{i}\right)$ is also the Index of Access value for each location (i)

$$
A_{i}=\Sigma j \in\left[d_{i j}<d_{\max }\right] R_{j} * f\left(d_{i j}\right)
$$

Figure 1. Two-step floating catchment area (2SFCA) method overview. Distance decay functions $f\left(d_{j k}\right)$ and $f\left(d_{i j}\right)$ are additionally shown (range between $0=$ full distance decay and $1=$ no distance decay) and a health needs weighting function $\mathrm{HN}_{k}$ in STEP 1 (range 1.0 to $1.5=50 \%$ higher needs) is shown as well. 
paredness to travel increase markedly, in tandem, in more sparsely settled areas. The defined (maximum) catchment sizes, measured as the travel time between residents and services, were 30 minutes in metropolitan areas, 45 minutes in rural areas, expanding to 70 minutes, 120 minutes and 200 minutes in the three more remote catchment areas. Additionally, a smoothing function was used to avoid sudden catchment size changes at the borders of each remoteness level (McGrail and Humphreys, 2014), and a capping function was used to avoid large metropolitan populations inappropriately modelled as overloading nearby small rural fringe services (McGrail and Humphreys, 2009c).

Data used to construct the national Index of Access were collected from several sources, with data relating to service availability collected from two sources. First, the volume of general practitioner (GP) services, (measured using fulltime equivalent counts) at each rural community was collected for July 2011-June 2012 from the Australian Government's Medicare Benefits Schedule. Because it relates essentially to service billing, this dataset is highly accurate and up-to-date, and contains close to $100 \%$ coverage of GP encounters. Rural communities were defined by the geography of the ABS's Urban Centres and Localities. Secondly, metropolitan GP service counts by postcode were collected from the Australasian Medical Publishing Company as of April 2012. Although metropolitan access was not the focus of this study, these data enable the 2SFCA method to capture metropolitan fringe activity, thereby allowing calculation without gaps in a national-scale measure of access.

Thirdly, resident locations, population size and surrogate variables for health needs were collected from the ABS's 2011 census data. These data were aggregated at the Statistical Area level 1 (SA1) in rural areas (average 400 residents per SA1) and at the SA2 level in metropolitan areas (average 10,000 residents per SA2). Chosen components and weightings for primary health needs were based on earlier measures shown empirically to provide valid approximations (Field, 2000; McGrail and Humphreys, 2009c). A composite health needs measure was calculated by aggregating three key components: i) $50 \%$ weighting to socio-economic status using the Index of Relative Socio-economic Disadvantage (ABS, 2013); ii) 25\% weighting to indigenous population $\%$ counts; and iii) $25 \%$ weighting to the per cent population either very young (0-4) or old (65+). All data for the three health needs components came from the ABS's 2011 census. Communities with below average health needs (that is, they are relatively healthy) were giving a weighting of $100 \%$ (no change), whilst the maximum weighting applied to the highest need community was about $150 \%$. Approximately
$10 \%$ of rural communities had a weighting above $130 \%$, a further $28 \%$ with a weighting of $120-130 \%, 37 \%$ with a weighting of $110-120 \%$ and $25 \%$ with a weighting of $100-110 \%$.

The fourth data component was the national road network, supplied by MapData Services Australia. Using ArcView 9.2 (ESRI, Redlands, CA, USA), the Closest Facility tool of the Network Analysis module was used to determine network routes and calculate proximity between population locations and service locations. Travel time was used as the measure of impedance by combining road section lengths and approximate travel speeds. With the exception of the island state of Tasmania, all other islands were removed from access calculations.

All four datasets were imported into Microsoft Access 2010 to complete the 2SFCA method calculations as per the Step 1 and Step 2 equations in Figure 1. The number of services (full-time equivalent) per rural community or metropolitan postcode defined $S_{j}$ whilst the resident population size per rural (SA1) or metropolitan (SA2) region defined $P_{k}$. Distance-decay functions, $f\left(d_{j k}\right)$ and $f\left(d_{i j}\right)$, were defined using a continuous function with no decay applied in the first 10 minutes, full decay beyond the catchment boundary and $\left(\left(d_{\max }-d\right) /\left(d_{\max }{ }^{-}\right.\right.$ 10) $)^{\wedge} 1.5$ for proximity=d otherwise, whilst maximum catchment sizes, $d_{\max }$, were defined as per the five remoteness levels described above.

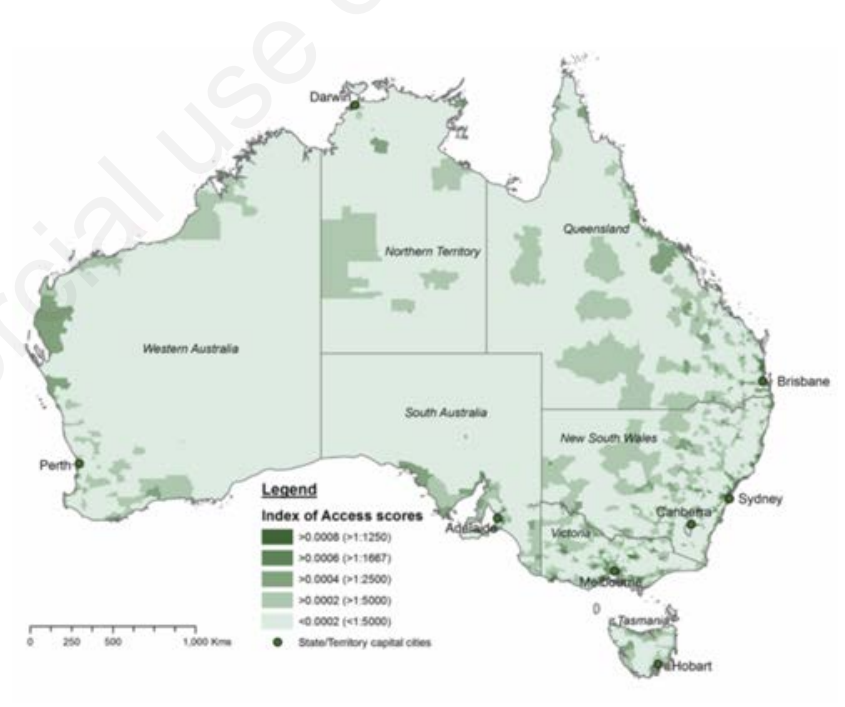

Figure 2. Index of Access map: whole of Australia.

Table 1. Distribution of Index of Access scores by State and geographical remoteness (\%).

\begin{tabular}{|c|c|c|c|c|c|c|c|c|c|c|c|c|c|c|c|c|c|c|c|c|}
\hline \multirow[b]{2}{*}{$\begin{array}{l}\text { Index } \\
\text { of Access scores }\end{array}$} & \multirow[b]{2}{*}{$\begin{array}{l}\text { Inner } \\
\text { regional }\end{array}$} & \multicolumn{3}{|c|}{ Australia (whole) } & \multicolumn{4}{|c|}{ New South Wales } & \multicolumn{4}{|c|}{ Queensland } & \multicolumn{4}{|c|}{ Victoria } & \multicolumn{3}{|c|}{ Western Australia } & \multirow[b]{2}{*}{$\begin{array}{l}\text { te Very } \\
\text { remote }\end{array}$} \\
\hline & & $\begin{array}{l}\text { Outer } \\
\text { regional }\end{array}$ & Remote & $\begin{array}{l}\text { Very } \\
\text { remote }\end{array}$ & $\begin{array}{l}\text { Inner } \\
\text { regional }\end{array}$ & $\begin{array}{l}\text { Outer } \\
\text { regional }\end{array}$ & Remote & $\begin{array}{l}\text { Very } \\
\text { remote }\end{array}$ & $\begin{array}{l}\text { Inner } \\
\text { regional }\end{array}$ & $\begin{array}{l}\text { Outer } \\
\text { reggional }\end{array}$ & Remote & $\begin{array}{l}\text { Very } \\
\text { remote }\end{array}$ & reggi & $\begin{array}{l}\text { Outer R } \\
\text { Aregional }\end{array}$ & Remote & $\begin{array}{l}\text { e Very } \\
\text { remote }\end{array}$ & $\begin{array}{l}\text { Inner } \\
\text { regional }\end{array}$ & $\begin{array}{l}\text { Outer } \\
\text { reggional }\end{array}$ & Remote & \\
\hline$(1)>0.0008(>1: 1250)$ & 10 & 5 & 0 & 0 & 9 & 3 & 0 & 0 & 11 & 11 & 1 & 0 & 6 & 7 & 0 & - & 0 & 0 & 0 & 1 \\
\hline (2) $>0.0006(>1: 1667)$ & 35 & 32 & 10 & 4 & 37 & 8 & 3 & 0 & 37 & 43 & 9 & 0 & 34 & 33 & 0 & - & 32 & 34 & 7 & 0 \\
\hline$(3)>0.0004(>1: 2500)$ & 30 & 29 & 40 & 10 & 26 & 38 & 20 & 0 & 32 & 20 & 42 & 7 & 33 & 27 & 12 & - & 27 & 24 & 31 & 14 \\
\hline (4) $>0.0002(>1: 5000)$ & 18 & 22 & 31 & 26 & 21 & 28 & 56 & 58 & 13 & 18 & 20 & 48 & 20 & 20 & 66 & - & 22 & 27 & 48 & 13 \\
\hline$(5)<0.0002(<1: 5000)$ & 7 & 12 & 18 & 59 & 7 & 22 & 22 & 42 & 7 & 9 & 28 & 45 & 6 & 14 & 22 & - & 18 & 14 & 13 & 72 \\
\hline tate population* & 18.5 & 9.2 & 1.4 & 0.9 & 18.6 & 5.9 & 0.4 & 0.1 & 20.5 & 14.8 & 1.7 & 1.3 & 19.6 & 4.5 & 0.1 & 0.0 & 9.1 & 7.9 & 4.3 & 2.7 \\
\hline
\end{tabular}

*Remainder of population in Australia and each State are classified as metropolitan. Inner regional, outer regional, remote and very remote (geographical remoteness) categories are defined by the Australian Statistical Geography Standard-Remoteness Area (ASGS-RA) classification. 
Lastly, the Health Needs weighting was applied in Step 1 by multiplying it to the population size, $\mathrm{P}_{\mathrm{k}}$ to model increased demand on available services $\mathrm{S}_{\mathrm{j}}$. In combination, these steps define the Index of Access scores for each rural SA1 in Australia. All index scores were calculated for the SAl geography, and collapsed into five categories for ease of use. Note that final decisions on the number of groups and the group cut-off points are somewhat arbitrary and often best decided by the purpose of the end-user. Whilst access scores are in the form of PPRs (for example, 0.0008 equals a ratio of 1 provider to 1250 residents), these have been adjusted by distance-decay functions in both Steps 1 and 2 and health needs in Step 2 of the 2SFCA method. Thus, they should not be directly compared to other reports using crude PPR methods.

\section{Results}

The national-scale map of access to PHC in Australia is displayed as a choropleth map in Figure 2 and summarised in Table 1. Figure 2 clearly shows that access was very poor across large portions of nonmetropolitan Australia, particularly in more remote (central) areas, which are characterised by the presence of few residents and extremely low population densities. However, as can be seen at the national level, access to PHC is far from equal across rural Australia. Whilst there is a general trend towards better access in rural areas more proximate to the large metropolitan populations and worse access in remote areas, this pattern is not always consistent. Table 1 reveals, using the ASGSRA classification, that $50-85 \%$ of residents in the two remote categories experience access in the lowest two categories, whilst the corresponding values for the two regional (rural, but not remote) categories are $25-34 \%$. These trends match the expected direction, but they also demonstrate a large level of variation in access within each remoteness category. Similarly, there are many rural areas exhibiting very poor access $(<0.0002)$ just as there are several remote areas exhibiting good access (>0.0006).

In order to better visualise the improved geographic sensitivity of this new measure, Figure 3 displays results for one state (the most populous one) within the national application of the Index of Access. It reveals, in finer detail than Figure 2, variations of PHC access in rural New South Wales (NSW). At this meso-level analysis, it is clear that access varies significantly between different parts of the state as well as within smaller sub-regions. The key strength of using data inputs at the finest available geographic resolution is that access scores can be differentiated at a much finer geographical scale than previously possible. Table 1 further summarises access scores for four states within Australia, including NSW. Interestingly, there is no significant variation between states in the range of access scores seen within each remoteness level. For example, within the inner regional areas of NSW, Queensland, Victoria and Western Australia, the distribution of access scores are similar, though Western Australia (Australia's largest state) does trend towards having more residents with poor access. One notable feature of Table 1, not apparent in Figure 2, is the greater number of NSW outer regional residents having poor access $(50 \%<0.0004$ compared to $34 \%$ nationally).

Another significant advantage of this new index is its ability to differentiate sensitively in relation to the notion of service shortage. Currently in Australia, District of Workforce Shortage (DWS) regions use the same Medicare Benefits Schedule data but are designated using only crude PPR methods to identify areas of poor (defined as below average) access, with strong similarities to the Health Professional Shortage Area designations in USA (Luo and Qi, 2009;
Ricketts et al., 2007). The DWS measure is a binary outcome only. Problems associated with using this simplistic approach to measuring access (McGrail et al., 2011) are further emphasised when compared with the Index of Access scores. Table 2 highlights the weakness of using DWS status by comparing results against the finer discrimination enabled by the Index of Access. Tested on a stratified random sample of 135 rural and remote towns, it can be seen that most DWS status towns has a lower average access score. However, Table 2 also shows that there exist many rural towns with seemingly incorrect DWS status. Use of the Index of Access identifies a significant proportion of towns characterised by low access that are not categorised as DWS status, as well as many towns characterised by good access that are categorised as DWS status.

\section{Discussion}

The purpose of any geographical classification is to ensure that populations sharing similar characteristics fall within the same category.

Table 2. Distribution of Index of Access scores by district of workforce shortage status.

\begin{tabular}{lcc} 
Index of Access scores & Not DWS status $(\mathrm{n}=48)^{*}$ & DWS status $(\mathrm{n}=87)^{*}$ \\
Median & $6.1 \times 10^{-4}$ & $3.9 \times 10^{-4}$ \\
Minimum & $2.6 \times 10^{-4}$ & $4.5 \times 10^{-4}$ \\
\hline Maximum & $9.5 \times 10^{-4}$ & $9.8 \times 10^{-4}$ \\
25 th percentile & $4.6 \times 10^{-4}$ & $2.9 \times 10^{-4}$ \\
\hline 75 th percentile & $7.1 \times 10^{-4}$ & $5.3 \times 10^{-4}$ \\
$<0.00040(\%)$ & 17 & 53 \\
\hline $0.00040-0.00055(\%)$ & 25 & 25 \\
$0.00055-0.00070(\%)$ & 23 & 14 \\
\hline$>0.00070(\%)$ & 35 & 8
\end{tabular}

DWS, district of workforce shortage. *Stratified random selection of 135 non-metropolitan towns: New South Wales, Victoria, Queensland - 25 each; Western Australia, South Australia - 20 each; Northern Territory, Tasmania - 10 each. Strata used were State/Territory, population size (maximum 100,000 residents), coasta/inland location and geographical remoteness.

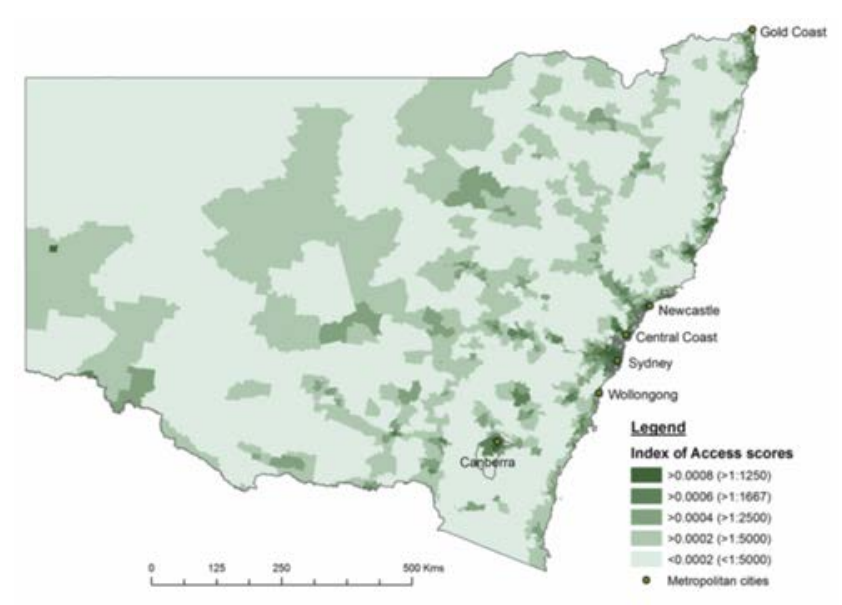

Figure 3. Index of Access map: state of New South Wales. 
Development of this new Index of Access was done with the aim to better achieve the statistical goal of minimising within-group variation [where each category is relatively homogeneous with respect to the factor(s) of interest] and maximising between-group variation. Through aggregating the three critical components stated (availability, proximity and health needs), the national Index of Access provides an improved measure of spatial accessibility for identifying areas with access disparities and a potential workforce-planning tool. Spatial access to health services remains the key disadvantage for many rural communities, and this study provides a new approach to identifying access disparities, which is suitable for macro-level analysis. For too long, governments and health service planners have relied upon the use of inadequate access measures.

Two design components ensure that the Index of Access is underpinned by an appropriate measure of potential demand (utilisation). First, the 2SFCA method defines service and population catchments, which are centred on the actual service and residential locations. In addition, these catchments are sized relative to the local geography, with more remote areas having larger catchments. Second, demand is measured not just by the population size, but is also weighted according to health need within its measurement. Whilst measures of deprivation by themselves have been investigated as predictors of health care access (Butler et al., 2013), the Index of Access provides a composite measure of access that accounts for health need within its measurement.

Many current rural health policies in Australia are linked solely to the concept of geographical remoteness (Mason, 2013), such that communities located most remotely from large populations receive the greatest support and the least remote locations receive proportionately less support. In this case, remoteness reflects the geographical separation from large metropolitan areas and other regional centres. Whilst access is often associated with geographical remoteness (Table 1) the use of a specific measure such as the Index of Access highlights one of its key advantages to better identify spatial disparities of access within and between regions, which can exist in all parts of non-metropolitan Australia irrespective of rurality or remoteness designation.

A number of limitations characterise this study. The authors recognise that the concept of access is much more complex than the three components of availability, proximity and health needs. However, in the absence of data at a suitable geographic scale, inclusion of additional measures was not possible, and it remains unclear what difference other components may contribute to access measurement. For example, acceptability often constitutes an important consideration for some sub-groups of the population, such as females wishing to see a female GP or Indigenous people wanting to see an Aboriginal Health Worker (AIHW, 2014; Ward et al., 2015). However, without suitable national data, it remains unclear how these preferences influence PHC-seeking behaviour, and it is not yet possible to model them within a nationalscale geographical classification. Moreover, applications to other jurisdictions may require additional components, such as affordability where universal access is unavailable or mobility/transportation where car usage is less common.

This study used the best available (albeit limited) empirical research to guide health seeking behaviour amongst rural populations (Ward $e t$ $a l ., 2015)$. Whilst access to health care is widely researched, very few studies attempt to rank the importance of the various components of access. Although this research employed the results of one small substudy of five different rural populations to guide decisions relating to catchment sizes in more sparsely populated areas (McGrail and Humphreys, 2014; Ward et al., 2015), more comprehensive evidence is required particularly in relation to the most remote geographical areas.
Also, despite using the smallest available spatial scale, a finer geographic resolution may be needed for very sparsely populated remote areas than currently exists.

Measurement of spatial access was limited to GPs, the only reliable dataset available at the national level. Nonetheless, the methodology underpinning the Index of Access reported here is equally appropriate for other PHC services, such as dentists, pharmacists and most allied health services. Moreover, this study has only utilised the road network, with an underlying assumption that residents mostly use a vehicle to travel to health services. This approach cannot measure access in remote islands where services are often only reachable by air or sea. Additionally, this study has not accounted for seasonal changes to road conditions, particularly in the northern areas of Australia, where roads are often impassable during wet season. It is also recognised this method is less applicable to countries with higher proportions of travel to healthcare independent of motor vehicles or travel routes outside of the road network.

\section{Conclusions}

The Index of Access provides a unique and significantly-improved contribution to guide rural health service and workforce planning in the provision of PHC services. With governments striving to improve equity of access to primary health care and knowing that rural populations have long had poorer access, this new access measure enables much improved identification and finer resolution of spatial disparities and specific areas characterised by poor access.

The Index of Access has many potential applications in macro-level health policy and planning. Firstly, identification of poor access areas can be used to better target workforce recruitment and retention programmes. Secondly, accurate access scores can provide more specific location information to local service planners in relation to where to target workforce incentives and support. Thirdly, workforce planners can evaluate the effect of changes in service provision on patient access, helping to assess both risks and benefits of workforce programmes as well as a better basis for evaluating the effectiveness of their policies. This new national-scale Index of Access provides a timely solution to the identification of areas of low or high access for use by planners and policy makers in support of equity of access.

\section{References}

ABS, 2011. Australian statistical geography standard (ASGS). Vol 5. Remoteness structure. Australian Bureau of Statistics, Canberra, Australia.

ABS, 2013. Census of population and housing 2011: socio-economic indexes for areas (SEIFA), Australia. Australian Bureau of Statistics, Canberra, Australia.

AIHW, 2008. Rural, regional and remote health: indicators of health status and determinants of health. Australian Institute of Health and Welfare, Canberra, Australia.

AIHW, 2014. Access to primary health care relative to need for indigenous Australians. Australian Institute of Health and Welfare, Canberra, Australia.

Bullen N, Moon G, Jones K, 1996. Defining localities for health planning: a GIS approach. Soc Sci Med 42:801-16. 
Butler D, Petterson S, Phillips R, Bazemore A, 2013. Measures of social deprivation that predict health care access and need within a rational area of primary care service delivery. Health Serv Res 48:539-59.

Buzza C, Ono SS, Turvey C, Wittrock S, Noble M, Reddy G, Kaboli PJ, Reisinger HS, 2011. Distance is relative: unpacking a principal barrier in rural healthcare. J Gen Intern Med 26:648-54.

Field K, 2000. Measuring the need for primary health care: an index of relative disadvantage. Appl Geogr 20:305-32.

Guagliardo MF, 2004. Spatial accessibility of primary care: concepts, methods and challenges. Int J Health Geogr 3:3.

Higgs G, 1999. Investigating trends in rural health outcomes: a research agenda. Geoforum 30:203-21.

Hu R, Dong S, Zhao Y, Hu H, Li Z, 2013. Assessing potential spatial accessibility of health services in rural China: a case study of Donghai county. Int J Equity Health 12:35.

Humphreys JS, Solarsh G, 2008. At-risk populations: rural. In: Heggenhougen HK and Quah S, eds. The international encyclopedia of public health. Academic Press, London, UK.

Jones C, Parker T, Ahearn M, Mishra A, Variyam J, 2009. Health status and health care access of farm and rural populations. United States Department of Agriculture, Economic Research Service, Washington, DC, USA.

Kulig J, Williams A, 2011. Health in rural Canada. UBC Press, Vancouver, BC, Canada.

Levesque J-F, Harris MF, Russell G, 2013. Patient-centred access to health care: conceptualising access at the interface of health systems and populations. Int J Equity Health 12:18.

Luo W, Qi Y, 2009. An enhanced two-step floating catchment area (E2SFCA) method for measuring spatial accessibility to primary care physicians. Health Place 15:1100-7.

Luo W, Wang F, 2003. Measures of spatial accessibility to health care in a GIS environment: synthesis and a case study in the Chicago region. Environ Plann B 30:865-84.

Luo W, Whippo TL, 2012. Variable catchment sizes for the two-step floating catchment area (2SFCA) method. Health Place 18:789-95.

Mason J, 2013. Review of Australian Government Health Workforce Programs. Australian Government Department of Health, Canberra, Australia.

McGrail MR, 2012. Spatial accessibility of primary health care utilising the two step floating catchment area method: an assessment of recent improvements. Int J Health Geogr 11:50.

McGrail MR, Humphreys JS, 2009a. A new index of access to primary care services in rural areas. Aust NZ J Publ Health 33:418-23.

McGrail MR, Humphreys JS, 2009b. Geographical classifications to guide rural health policy in Australia. Aust NZ Health Policy 6:28.

McGrail MR, Humphreys JS, 2009c. The index of rural access: an innovative integrated approach for measuring primary care access. BMC Health Serv Res 9:124.

McGrail MR, Humphreys JS, 2014. Measuring spatial accessibility to primary health care services: utilising dynamic catchment sizes. Appl Geogr 54:182-8.

McGrail MR, Humphreys JS, Joyce C, Scott A, Kalb G, 2011. Rural amenity and medical workforce shortage: is there a relationship. Geogr Res 49:192-202.

McGrail MR, Humphreys JS, Ward B, 2015. Accessing doctors at times of need-measuring the distance tolerance of rural residents for health-related travel. BMC Health Serv Res 15:212.

Penchansky R, Thomas JW, 1981. The concept of access: definition and relationship to consumer satisfaction. Med Care 19:127-40.

Ranga V, Panda P, 2014. Spatial access to in-patient health care in northern rural India. Geospat Health 8:545-56.

Ricketts TC, Goldsmith LJ, Holmes GM, Randolph R, Lee R, Taylor DH, Ostermann J, 2007. Designating places and populations as medically underserved: a proposal for a new approach. J Health Care Poor U 18:567-89.

Russell D, Humphreys JS, Ward B, Chisholm M, Buykx P, McGrail M, Wakerman J, 2013. Helping policymakers address rural health access problems. Aust J Rural Health 12:61-71.

Sibley L, Weiner J, 2011. An evaluation of access to health care services along the rural-urban continuum in Canada. BMC Health Serv Res 11:20.

Starfield B, 2006. State of the art in research on equity in health. J Health Polit Polic 31:11-32.

Tanser F, Gijsbertsen B, Herbst K, 2006. Modelling and understanding primary health care accessibility and utilization in rural South Africa: an exploration using a geographical information system. Soc Sci Med 63:691-705.

Thomas SL, Wakerman J, Humphreys JS, 2014. What core primary health care services should be available to Australians living in rural and remote communities? BMC Fam Pract 15:143.

Wakerman J, Humphreys JS, 2012. Sustainable workforce and sustainable health systems for rural and remote Australia. Med J Australia 1:14-7.

Wan N, Zou B, Sternberg T, 2012. A 3-step floating catchment area method for analyzing spatial access to health services. Int J Geogr Inf Sci 26:1073-89.

Wang F, Luo W, 2005. Assessing spatial and nonspatial factors for healthcare access: towards an integrated approach to defining health professional shortage areas. Health Place 11:131-46.

Ward B, Humphreys JS, McGrail MR, Wakerman J, Chisholm M, 2015. Which dimensions of access are most important when rural residents decide to visit a general practitioner for non-emergency care? Aust Health Rev 39:121-6.

WHO, 1978. Declaration of Alma-Ata. Paper presented at the International conference on primary health care. WHO Press, Geneva, Switzerland.

WHO, 2013. World health statistics 2013. WHO Press, Geneva, Switzerland. 